Article

\title{
Structures of the Public Sphere: Contested Spaces as Assembled Interfaces
}

\author{
Cornelia Brantner ${ }^{1, *}$, Joan Ramon Rodríguez-Amat ${ }^{2}$ and Yulia Belinskaya ${ }^{3}$ \\ ${ }^{1}$ Department of Geography, Media and Communication, University of Karlstad, Sweden; E-Mail: cornelia.brantner@kau.se \\ 2 Department of Media Arts and Communication, Sheffield Hallam University, UK; E-Mail: mon.rodriguez@shu.ac.uk \\ ${ }^{3}$ Department of Communication, University of Vienna, Austria; E-Mail: yulia.belinskaya@univie.ac.at \\ * Corresponding author
}

Submitted: 15 December 2020 | Accepted: 7 May 2021 | Published: 23 July 2021

\begin{abstract}
This article updates certain aspects of the normative notions of the public sphere. The complex ecosystem of social communications enhanced by mobile media platform activity has changed our perception of space. If the public sphere has to normatively assess the expected conditions for public debate and for democracy, the assemblage of devices, discourses, infrastructures, locations, and regulations must be considered together. The literature reviewed about the public sphere, spaces, and geographically-enabled mobile media leads this article to the formulation of a concept of the public sphere that considers such assemblage as an interface. As an empirically applicable update to the definition of the public sphere the text offers a model that helps analyze those factors considering how they shape the communicative space in four modes: representations, structures, textures, and connections. These modes consider the roles played by assemblages of devices, infrastructures, and content in delimiting the circulation of information. The second part of the article illustrates the model with examples from previous research, paying particular attention to the structures' mode. The dissection of qualitative, quantitative, and geodata generated by digital and (visual) (n)ethnographic tools reveals three subcategories for the analysis of structures of space: barriers, shifts, and flows. The structures effectively enable/disable communication and define centers and peripheries in the activity flows. The contribution of this article is, thus, conceptual-it challenges and updates the notion of the public sphere; and methodological-it offers tools and outputs that align with the previously developed theoretical framework.
\end{abstract}

\section{Keywords}

assemblage; geomedia; interface; mobile media; public space; public sphere; structures of space

\section{Issue}

This article is part of the issue "Spaces, Places, and Geographies of Public Spheres" edited by Annie Waldherr (University of Vienna, Austria), Ulrike Klinger (European University Viadrina, Germany) and Barbara Pfetsch (Freie Universität Berlin, Germany / Weizenbaum-Institute for the Networked Society, Germany).

(C) 2021 by the authors; licensee Cogitatio (Lisbon, Portugal). This article is licensed under a Creative Commons Attribution 4.0 International License (CC BY).

\section{Introduction: Shaping Spaces of a Challenged Public Sphere}

Mobile access to social media platforms has transformed the physical space of everyday communications, its representations, the understanding of it, and the conditions required to interact with and within it. This transformation significantly impacts the ways we 'connect' through media, and 'live' in places. The geography of those actions is relevant because mobile and social media have enabled "a new way to coordinate the move- ment of individuals in geographic space" (Abernathy, 2017 , p. 2). For example, collaborative map production generates new geographies for political interaction that are erected in the physical and virtual worlds simultaneously (Rodriguez-Amat \& Brantner, 2016). The impacts of such transformation also echo in the ways we live and govern ourselves. For example, social mediaenhanced protests and public events stretch the communicative spaces of social communication and challenge the Habermasian normative concept of the public sphere. 
And yet, the notion of the public sphere "remains a central analytical tool in modern society to help us make sense of the relationship between the media and democracy" (losifidis, 2011, p. 620). The concept still holds its heuristic and normative capacity even in complex environments of communicative interaction shaped by factors that condition the public debate. This article revisits the concept of the public sphere and suggests an update in the face of the rich, complex, and multilayered integrated-circuit of the geography of interactions online and offline as an assembled interface.

The second part of the article outlines a tool for the analysis of the configurations that shape such communicative spaces. That analysis is organized along four aspects: representations, structures, textures, and connections (Adams \& Jansson, 2012) that highlight the political dimension of the spatial struggle while identifying the multiple forces and factors that intervene in its negotiation. The article considers particularly the structures of space (Brantner \& Rodriguez-Amat, 2016; Rodriguez-Amat \& Brantner, 2016): The analysis of the wiring and shape of the communicative space returns as a conceptual update of the idea of the public sphere, because it considers the location and infrastructure of the communication process as structural conditions for public debate. Such an update involves understanding the public sphere in three ways: The public sphere: (1) is a space of communicative (inter)action; (2) is an environment of political debate that integrates communication devices and content; and (3) challenges the conditions of legitimacy.

\section{Public Sphere: The Heuristic Capacity of a Classic}

Arendt coined the concept of the public sphere (Öffentlichkeit) in 1951, which was crystallized later in Habermas' (1974) work: "A realm of our social life in which something approaching public opinion can be formed. Access is guaranteed to all citizens" (p. 49). That realm of 'undistorted communication' is characterized by its utopian independence from any supranational corporate platforms and state bureaucratic bodies.

The Habermasian notion of a functioning democratic public sphere has been criticized for its class unawareness (Negt \& Kluge, 1973), its focus on "the bourgeois public sphere as an ideal type" (Garnham, 2007, p. 207), and for other structural barriers based on multiculturality (Walzer, 1999), race (Jacobs, 1999), and gender (Fraser, 1996). Castells (2008) discussed the crisis of nation-state public spheres and argued that the new technological means could enable global civil society to organize itself properly.

As early as 20 years ago, the economic autonomy of the virtual public sphere was questioned, as was the commercialization of 'cyberspace' (Sparks, 2001; Thomas \& Wyatt, 1999). Following Habermas (2006), Geiger (2009) stated that computer-mediated communication has "a 'parasitical' role to play in the public sphere, largely due to the way in which Internet-based discourse communities have fragmented the public" (p. 2). The fragmentation of the public, the overwhelming amount of information, and the existence of echo chambers (Colleoni et al., 2014) are ambiguous concepts that veil the dark side of digital politics (Treré, 2016). Identifying the features of this complex and politicized digital online environment is essential if the purpose is to update and conceptually challenge the fundamental normative approach while providing empirical opportunities for actual research. But below those limitations, the heuristic capacity of the public sphere concept as the area of contact between civil society and its regulation, the means that enable social-civic interaction, and the resulting public law binding debate, should not be underestimated.

This article intends to show that the public sphere is more than the arguments forming the debate on political issues. A proper conceptualization needs to take into consideration the debates but also the infrastructures that enable it. Mouffe (2005) points out that we need a broader notion of public sphere that goes beyond institutionalized politics, because defining politics in that narrow sense would miss the political dimension of the social; but, we add, we also need a notion of public sphere that incorporates the location and the extension of infrastructures that enable its activity. The public sphere, thus, must be understood as an inclusion of debates and spaces, devices and voices, access and content-as a complex integrated circuit. The research program developed here, around communicative spaces, expands that discourse-centered notion of public sphere (see, e.g., Ferree et al., 2002) towards the inclusion of all those conditions and their possibilities of transcending and achieving political relevance.

\subsection{Hybridities and the Public Sphere}

In the last decade, the culture of protests has grown and entwined with the development of mobile devices with Internet access. Social media platforms have become key spaces to expand, extend, and multiply the geographical range of the activity on the streets. Participants in urban actions interact virtually and physically, thus expanding the same notion of social interaction. Protests, indeed, are a good example of the redefinition of the public sphere because they challenge the established spatial order of cities, subverting the pattern of the urban ideology, and sustaining with it, symbolic struggles. The places projected through mobile, online, and material interactions embody a paradigmatic geographical shift represented by works on cities (Sassen, 2006), mediacities (Eckardt, 2008), platforms (Grech, 2015), networks (Castells, 2008), ubicomp infrastructure mess (Dourish \& Bell, 2011), or mobile interfaces (de Souza e Silva, 2006; Farman, 2012).

The effort to grasp this fluidity of communicative action was fruitful: Chadwick (2013) referred to hybridity 
to study the assemblages of journalists, technologies, and political actors in the current media ecosystem. He applied this later to citizen movements to show "how even the most obviously 'digitally-native' political activism has now evolved to the point where much of the daily practice involves the integration of older and newer media, in a hybrid mix" (Chadwick \& Dennis, 2017, p. 45). Hybridity was also an arrival point for Treré (2018) to crack open the complexity of media activism in contemporary culture. These are fertile attempts; they merge the augmented activity of social media and protests and open opportunities for refreshing thoughts about activism, but the geographic relevance of the events seems to pass unnoticed. Virtual interactivity, indeed, challenges the public sphere enabled and extended by mobile and online environments, enhancing a powerful sense of place.

This shared space results from hybrid collective communicative action. Social media interaction happens simultaneously to the actual political action of occupying urban space, forcing a whole new socio-organizational principle of self-other and world that carries consequences for social relations (Lapenta, 2011). Taking into consideration the further fragmentation and individualization of digital publics, Bennett and Segerberg (2012) juxtapose the logics of collective and connective action, endowing the latter with more individualized orientations, replacing old organizational mechanisms. The politicized communicative space is an area of interactivity, and the whole communicative action becomes a form of multilayered public sphere with a redefined sociality.

\section{A Contested Notion of (Public) Space}

If the notion of public sphere is contested, so is the notion of public space. The axis public-private is a common reference for the understanding of modern societies, but its fitting with space is problematic: "The conceptual and spatial senses of a public sphere are given to run together, but it is not always clear how-if at all-public spaces relate to notions of a public sphere" (Tonkiss, 2005, p. 66). Such spatial tension between the public and the private thus reaches the notion of the public sphere problematically.

For Tonkiss there are three ideal types of public space: the square as space of collective belonging and as an expression of citizenship; the café as a site of sociality, not taking into account the question of ownership but highlighting the café's role as a space of social interaction; and the street, as a mundane space of communal use, a landscape of marginal encounters. These three types differ in what they socially-interactively-enable. This is an inspiring first conceptual and analytical step that links public space and public sphere.

But the relationship is more complex and problematic. Inhabiting the city relates to an urban ideology connected to industrial capitalism, and urban layouts designed as architectures of privilege and author- ity (Harvey, 2010). Space is a social construct (Lefebvre, 1991) that renders the bidirectional spatial relations between power and politics (Tonkiss, 2005): Power is defined by space, and space is where politics and power are staged.

The infrastructures of telecommunications have wired the world and new policies have been put in place: Discontinuing GPS selective availability by the Clinton legislation in 2000 allowed anyone to extract the exact location coordinates and to link them to the Internet. That move, parallel to the extension of the Internet with Wi-Fi, made the Internet ubiquitous. The strong homogenizing drive led to extenuating market competition for digital mapping and the control of GPS-enabled devices, triggering debates in the political economy of locative media (Barreneche, 2012). These factors have also changed the nature of the politicized space.

Ubiquitous geolocated devices and access to networks have led to an unprecedented amount of locationbased data. Access to participatory spaces has transferred to a system of passwords and codes (Adams \& Jansson, 2012) and such participatory "projects amalgamate media content, data overlays and real-time location data with the aim of re-politicizing urban space and uncovering the hidden, layered subjectivity of urban spaces" (Jethani \& Leorke, 2013, p. 488). Now, space is also transparent: CCTV circuits and surveillance cameras hold public space under siege, mobile devices are traceable, and users routinely checking in on social media enable permanent forms of corporate-, peer-, and selfsurveillance (Humphreys, 2011). Such extensive observation of communication in public space renders public activity transparent and monitored at the same time. The intuitive distinctions between public, private, and transparent spaces set a new regime of publicnessa form of disowned tax-free publicness systematically ring-fenced by an expansive corporate gesture of platformization (Van Dijck et al., 2018). Such regime claims an update of the notion of public sphere.

\subsection{Towards a Notion of Public Sphere in the Era of the Geoweb}

The new spatial regime under the wired, interwoven world web also changes the conditions for knowledge. The confluence of mobile media movements, crowdmapping, and digital connectivity of devices (Massey \& Snyder, 2012) changes the sense of place: Information flows accelerating across multiple territorial networks open new epistemic challenges. For example, protesters can communicate, share and publish violent, excluded, or occupied areas. The resulting spaces produced in those settings form a conglomerate of information that combines places with digital, collective, and GPS-enabled spaces (Brantner \& Rodriguez-Amat, 2016). Also, digital maps and interfaces have multiplying effects: The increase in information that reifies spatial data turns the map into a live text that never ends, and "displaces 
the author's central position in social space with a multiplicity of author positions" (Adams \& Jansson, 2012, p. 303). Mapping is a form of representing and is not a neutral practice: Mapping is political (Brantner \& Rodriguez-Amat, 2016; Rodriguez-Amat \& Brantner, 2016) and maps are social agents with political implications concerning the politics behind, within, and through them (Dodge, 2014).

The debates on the meaning of place, space, and mapping have entered media studies with the 'spatial turn' (Abernathy, 2017; Adams \& Jansson, 2012) and its extension, 'mobility turn' (Urry, 2007). Moreover, these turns are also strongly linked to the 'material turn' (Adams \& Jansson, 2012; Jansson, 2007; Morley, 2009), a "turn towards the conditions and practices (constellations and movements of people and objects) which put communication in (or out of) place, as well as towards the spatial materialities and sensibilities of communication" (Jansson, 2007, p. 186). These turns have made geographies imperative, and the broadened notion of communication embraces material conditions, bringing geoweb (Abernathy, 2017), locative media (Zeffiro, 2012), and geomedia (Lapenta, 2011) to the center of an emerging academic discussion.

Geolocated practices enable the examination of relationships between geolocated phenomena and other surrounding information defining a new knowledge politics, and transforming seeing and viewing (Elwood \& Leszczynski, 2013) as, for instance, in the case of the Occupy movement in 2011. 'Neogeographers' (Goodchild, 2009) produce map mash-ups that not only link people and information to specific places by "constructing hypergeographies of action and potential," but also encourage "users to visualize themselves and local events as part of a process of \#globalchange" (Massey \& Snyder, 2012, para. 34).

The production and elaboration of mapping and data visualization carry and extend the abstract notion of space while building communicative spaces as complex integrated circuits. Political views are newly articulated together with the extension of a politicized space simultaneously virtual and physical, mediated, networked, and on the ground, as well as global and local. Massey and Snyder (2012) concluded that the collection of data from dispersed Occupy events happening in different time and space coordinates, integrated and united a counter-public contesting state and corporate control of urban places. Such an extended environment across the virtual-material online and physical space raises a relevant discussion about the integrated space that forms an area of contact-the interface, the medium, an environment-that invites an updated approach to the concept of public sphere.

\subsection{The Public Sphere as an Interface}

Following Habermas (1991), Schlesinger (1999) states that popular involvement in public affairs and parliamen- tary democracy demands discursively structured public networks and arenas: "To put it simply, a communicative space" (p. 266). Such communicative space includes the 'new social operating system' (Rainie \& Wellman, 2012) and the notions of space and territory progressively defined by data collections, interfaces, and software as well as the physical, material, and geographic notion of space. Public spheres become spaces of communicative exchange, i.e., abstract interfaces that enable the approach to the idea of communicative space and its governance in a whole new manner.

Following Deleuze and Guattari, Chadwick et al. (2016, p. 10) referred to assemblage theory to stress that:

The hybrid media system approach shows, for example, that political news making is now carried out in such assemblages, as digital technologies enable individuals and collectivities to plug themselves into the news making process, often in real time, and strategically, across and between older and newer media settings.

On the other hand, DeLanda (2006) updates the Deleuzian principle of assemblage bringing it closer to Giddens' regionalized 'locale.' DeLanda's assemblage explains his approach to cities that are composed of inhabitants, networks and organizations, and "can hardly be conceptualized without a physical infrastructure of buildings, streets and various conduits for the circulation of matter and energy, defined in part by the spatial relations to one another" (p. 94). The spatial grounding of DeLanda's theory on city combines with the hybrid media theory to scaffold and release a fruitfully analytical and conceptual approach to the complex assemblages that are the communicative spaces: Interactions, devices, and location form networks of debates around a topic or lead towards public action.

Scolari (2018) and de Waal (2014) have used the idea of interface to talk about urban spaces and smart cities: "Where collective practices take shape, and when these collective practices change, the shape and meaning of the physical environment changes with them" (de Waal, 2014, p. 21). Both principles-cities as interfaces, and cities and media as assemblages-open an opportunity for this current approach to the study of the public sphere. This can incorporate, among other areas, the analysis of social networks (Scott, 2017) towards an understanding of aspects of the communicative space as a relational assembled environment.

These approaches lay the basis for a model of analysis of the communicative space. The consideration of the public sphere as an interface opens new critical possibilities of theoretical and empirical research because it permits the inclusion of spatial, infrastructural, interactive, and discursive levels. Accordingly, Elwood and Leszczynski (2013) analyze the interface level of digital interactive collaborative mapping. The concept of the interface as an area of contact is an opportunity 
for understanding forms of connection and communication across boundaries and systems (Manovich, 2001). Here, the communicative space is a complex environment of interaction, of political debates and territory, of the stages and conditions of access. The concept of interface and the notion of assemblage also enable the formulation of questions about which connections and what affordances are defined by and within the overall communicative environment.

The governance of communicative spaces consists then of the identification of factors that configure the affordances that enable or disable communicative interaction within the interface in which political debates happen: at the spatial, infrastructural, interactive, and discursive levels. Its analysis includes processes of diversity, negotiation and resistance (Schlesinger, 1999). The integrative concept of the communicative space as an interface, built as a circuit of political interaction, helps to include the assemblage of the press, the protesters, and their claims and posts on online platforms, as well as the platforms themselves and the possibilities of access, connection, and ownership. The analysis also includes the network of mobile devices considered against the place(s) and the geography of the interactions as well as the physical structures and barriers set by security forces-the factors that shape the broad, complex, multilayered public sphere as an interface.

\subsection{Shaping the Public Sphere: Governance of the Communicative Spaces}

The public sphere is not neutral or spontaneous; instead, it is shaped by limitations and restrictions of access to debate, flows of information, and spatial (in)equalities, and is shaped with intentions, policies, and boundaries. The conditions that wire any communicative space through policies or decisions about the technological infrastructures, interaction by interface design, or discourses are relevant because they have political implications, because they are expressions of a certain Weltanschauung (worldview), but also because they determine directly the quality of the underlying conditions for democracy.

The public sphere, therefore, is not only about discourses. It includes access, infrastructure, engagement, and interaction: The relational conditions that work as apriorisms that have been too long unseen. It is necessary to shift from an understanding of the public sphere as an abstract entity towards a concrete specific set of conditions with materiality, with relationships, with structure, with symbolic relevance, and with possibility. Here the notions of network and assemblage, in combination with the discursive analysis of the actual interactions and the consideration of the infrastructural conditions that work as integrative interfaces, make sense. Only with this conceptual shift is it possible to return to the public sphere in its heuristic capacity and as a critical concept that helps to assess democracy.

\section{The Model of Analysis}

Methodologically, it is necessary to develop tools and approaches that respect the complexity of that circuit. Former works developed an empirical model for the analysis of the factors that shape the communicative spaces. That model originated in a discussion about the disciplinary bridges between geography and communication by Adams and Jansson (2012). They suggested four areas of contact between disciplines: "Representations and textures relate closely to places, while structures and connections occupy and create spaces" (Adams \& Jansson, 2012, p. 306). These areas were turned into a tested analytical model (Belinskaya et al., 2019; Brantner \& Rodriguez-Amat, 2016; Rodriguez-Amat \& Brantner, 2016). This article cannot revisit all the applied cases in their extension but provides an overview of the model and insists on the structures of space to expand the conceptual and empirical research program on the governance of communicative spaces.

The model of analysis of communicative spaces is based on a social-constructivist approach to mediatization and integrates the multiple facets that shape complex communicative spaces defined in events like protests (Brantner \& Rodriguez-Amat, 2016; RodriguezAmat \& Brantner, 2016) or festivals (Belinskaya et al., 2019). The model offers a holistic, heuristic, and resilient set of tools that permits the integral analysis of multiple forms of expression. The four modes help to address complex nuances of the communicative space not only conceptually but also analytically, because the model avoids media-centric views and highlights the social and cultural aspects related to the power struggles and constraints mentioned earlier. Hence, the model does not entail a chronological step-by-step procedure, because the different modes influence and contextualize each other.

The representation mode analyses (social) media representations (Brantner \& Rodriguez-Amat, 2016) that show the diversity of competing narratives of place. Textures of place refer to the symbolic value of the locations by assuming that places communicate in themselves (Belinskaya et al., 2019). The structure mode directs our focus to the elements that allow or limit communication flows. Structures can be physical (e.g., walls, barricades) or 'virtual' (e.g., Wi-Fi passwords, media ownership, regulation, or phone jammers). The analysis of structures helps to identify centers and peripheries in the communication activity and highlights decisions, policies, or actions that effectively enable or disable interaction, while the mode of connections identifies the expanded network of links among the assemblage of actors.

The four-mode model has been tested on several protests and urban festivals. Protests generate contested spaces of engagement between the online and the urban space in assembled complex environments. Commercial urban festivals are also active events that engage public and fenced urban spaces, and that spread with activity 
across social media, and as they are planned events, their decision-making processes become more accessible to research. The authors analyzed protests in Madrid, Spain (September 2012), Vienna, Austria (January 2014), and Paris, France (April-June 2016), city festivals in Sheffield, England (July 2016, July 2017), and the Dance Days festival in Chania, Greece, (July 2018, July 2019). In all these cases results demonstrate the heuristic potential of the model.

\subsection{Beyond Representations}

Communicative spaces are social constructs and citizens understand them diversely: "Place representation is contingent and unique: Complexly situated with regard to power (Hall, 1980), no less than places themselves" (Adams \& Jansson, 2012, p. 307). To explore representations, it is necessary to analyze narratives about the space available throughout the extension of communicative practices. A protest in Vienna (Brantner \& Rodriguez-Amat, 2016) served as a case study for the detailed analysis of representations of space. The combination of qualitative and quantitative content analysis permitted the study of large volumes of (social) media representations, be they multimodal, images, or texts. For example, the quantitative-qualitative analysis of visual representations combines an image type analysis - which consists of a sorting task, in which downloaded images are sorted into different types as regards their representations of space and place-with in-depth analyses for selected prototypical images for each type. Moreover, the method can be combined with a quantitative analysis of content features, e.g., depicted people, place characteristics, accompanying texts, the results of which also inform the qualitative analysis. In the case of the protest in Vienna, the type of analysis was based on tweets including images. Moreover, the analysis was informed by Lefebvre's (1991) triad of space to apply three subcategories (Brantner \& Rodriguez-Amat, 2016): territorial representations, representations of location, and representations of activity. The systematic analysis of representations of space shows that multiple conflicting understandings and narratives emerge-they struggle to define the communicative space. In other words, the analysis of representations discerns which are the dominant representations and which perspective is allowed to name the space: occupied, liberated, free, or conflictual. In the case of commercial festivals, places termed (public) 'park,' 'playground,' or 'sports area' become (sealed off) 'VIP zone,' 'gates,' or 'stage.' Representations matter, and the analysis of the (social) media content shows which stories are made visible.

The diversity of views and negotiation of meanings might lead to the misunderstanding that they are the product of a healthy democratic debate, but such diversity of discourses and narratives, negotiating the meaning of the communicative space, must be contextualized. The communicative space is not a free space of confronted views (Treré, 2016), and analyzing the other three modes-structures, textures, and connectionshelps to show that lack of neutrality. Both media and (public) places are designed to favor certain visions (and representations) and to restrict others. The underlying coding is invisible to most users of place and media (Despard, 2016), but the hidden politics and biases of and behind the interfaces are relevant and must be taken into consideration (Frith, 2017), including those of and behind the shaping of places and spaces.

\subsection{Structures of Space}

Structures "define inequalities and power relations between those able to move and connect freely and those who are not able to" (Adams \& Jansson, 2012, p. 311). In this sense, the cultural activity emerging from communications in protests are situated, geolocated, and spatialized by "the architecture of dissent, the ways in which the physical structures and flows of a city directly affect the ability for people to gather, coordinate and maintain visible social movements" (Sadowski, 2014). This has a 'virtual' dimension too: regulation enforcement, interfaces, password-walled software platforms, surveillance vans, signal-jamming devices, access, profiling, and decisions by gatekeepers. Castells' (1989) term 'space of flows' describes the social relations emerging in the network society: "More important than the space of places, he argues, is the movement (of information, capital, people, ideas) between places" (Abernathy, 2017, p. 4). Structures are products of policies, decisions, or cultural settings and practices that coincide in their role of channeling information flows and enabling/disabling connections: the VIP wristbands, the stage pointing in one direction, prioritizing a directed information flow, the fences 'protecting' a single singer from the anonymous crowd. Structures are not only physical access to a protest or a festival venue; structures also involve regulation as described by Habermas (1991): The introduction of licensing or libel taxes for newspapers or restrictions on access to public coffeehouses limited the expression of opinion and access to information.

A mixed-method research project on an urban city festival-the Tramlines festival, in Sheffield-was designed for the exploration of structures of the communicative space (Belinskaya et al., 2019). Urban city festivals generate a communicative complexity similar to that of a demonstration but in an anticipated fashion: security, fences, venues, and the organization of the spaces are planned long ahead. The intentional transformation of initially publicly accessible places like parks into fenced-off areas, accessible only for a fee, raises immediate discussions about barriers, conditions of access, and the subsequent redesign of the conditions of communication. To explore this, the authors mixed digital and (visual) (n)ethnographic tools, interviews, mapping (GPX data), and representational resources (e.g., [social] media postings). The latter can also inform the analysis 
of structures, but as already outlined, media representations can provide information only about visible spatial structures (that are shown, or talked about).

The analysis of the ethnographic material and the data obtained via geotracking identified three subcategories of structures: barriers, shifts, and flows. The subcategories are defined by their roles in channeling information flows and work across devices, and across actual content (see Figure 1).

The three options deal with structures of sorts: physical, virtual, symbolic, proprietary, or regulatory. Barriers are mechanisms that stop the continuity of information flow. During the Tramlines festival 2016, the ethnographers drew fieldnotes-diagrams to show the structures and barriers in the main stage area (see Figure 1, left column top). In the case of demonstrations, police form cordons or set mobile barriers that channel the activity of protestors. Barriers are fundamental in policing but are also perceived by protesters as part of the confrontation with the forces of security. For example, a tweet from a protest in France (April 2016) mentions the arrival of lor- ries with fences and with "robocops" (police in anti-riot gear) as reinforcements.

This example represents a view, but points to the existence of (visible) structures, in this case fences, to stop and divert the flow of protesters (or audiences). There are other kinds of barriers: those formed by urban structures and streets. For example, regardless of whether the reason there was "no mobile network" (as one participant tweeted before the start of a demonstration in Madrid, in September 2012) was a mobile jammer or actual saturation of the mobile band, it acts as a barrier stopping the continuity of information flow. Structures should not be confused with representations. However, these two cases are picked as representations that point at structural aspects of the communicative space.

Shifts are mechanisms that work as valves, letting communication happen, or not. Examples are doors, passwords, press accreditations, ownership of mobile devices, or-in the case of festivals-the (ticket) wristbands and gates that activate the shifts, as shown in Figure 1 (middle column).
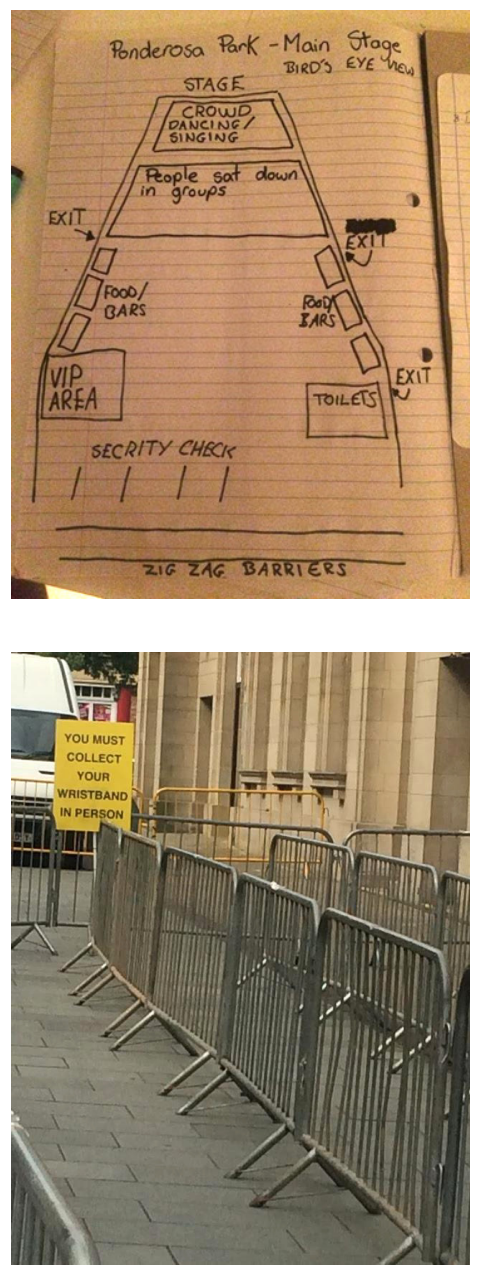

Barriers

(material, technologic, symbolic)
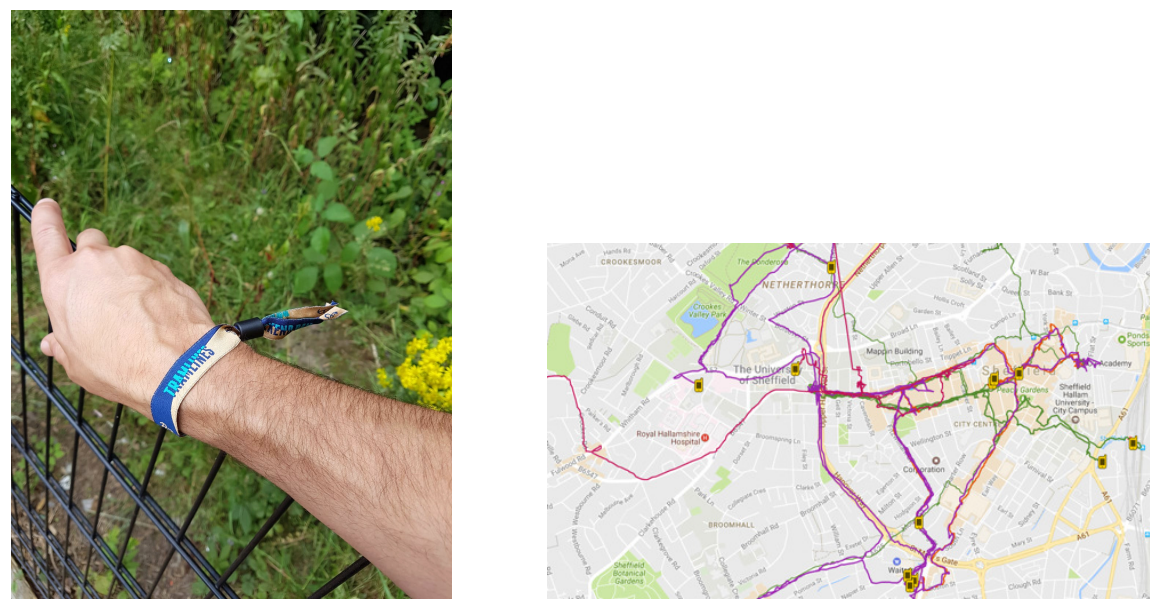

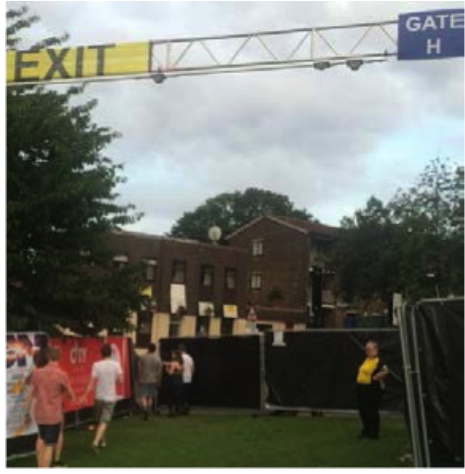

Shifts

(gates, codes, carriers)

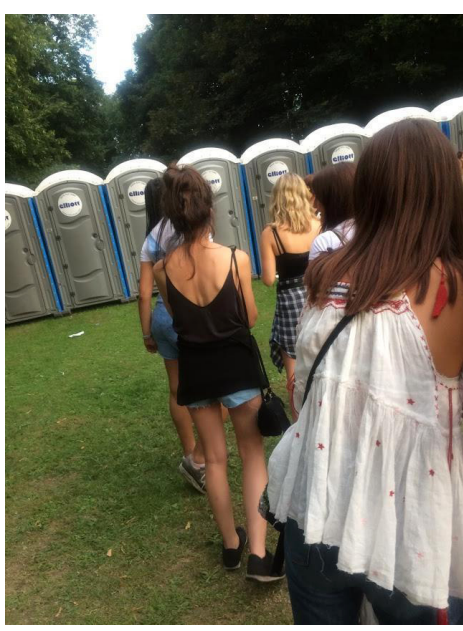

Flows

(hegemonic, negotiated, dissident)

Figure 1. Examples for barriers, shifts, and flows (captured by visual ethnography). 
Shifts are affordances defined by their capacity to selectively enable contact across a barrier; they are activated to open or truncate access. They can be physical, as in the case of the wristband that opens the fence for the concerts in a festival, or, coming back to protests, linguistic, as in the tweet in Figure 2 in which protesters in Paris' \#nuitdebout in 2016 translate debates into sign language. The barrier for hearing-impaired people is 'open' thanks to the presence of a translating shift of simultaneous sign-language.

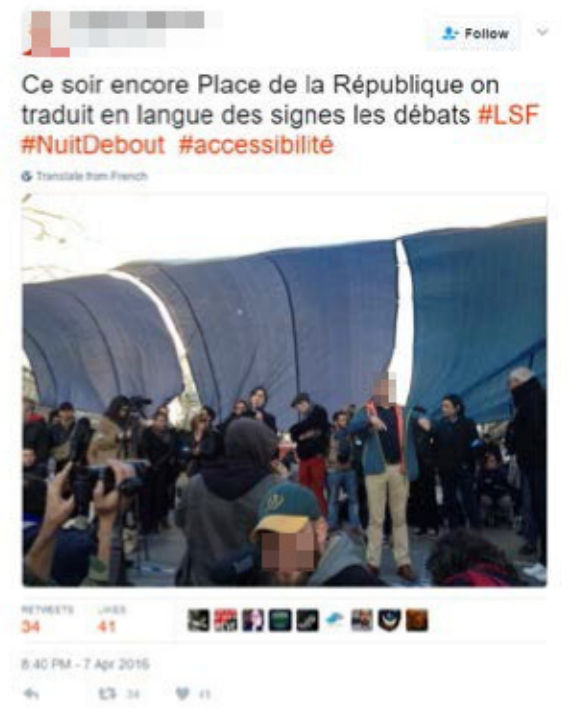

Figure 2. Tweet on \#nuitdebout visualizing sign-language translation. Note: We obtained the user's consent to reprint the tweet; username and faces of depicted people were pixelated to guarantee anonymity.

Flows are the substance of information in action. Flows are structures that keep the communication chains by themselves (or as a product of software or cultural norms); examples of flows are queues, as shown in Figure 1, bottom right. They include both transportation across space and informal interaction, similarly to what Tonkiss (2005) calls the street. Flows can, for instance, be identified in the cartography of the expansion of the demonstrations of \#nuitdebout published in the tweet shown in Figure 3 (also with permission from the author). Information flows from the center of Paris (Place de la République) to the periphery of the country. These flows can be mapped or traced across the territory and are part of the structures that stitch the communicative space.

Tracking the itineraries of the festival ethnographers enabled the visualization of flows defining the Tramlines city festival (see Figure 1, image top right). One can easily identify the centers and peripheries of the activity during the festival (particularly when overlapped with the geolocated tweets with the festival hashtag, shown on the map in Figure 4).

In the analysis of structures, ownership matters as soon as it conditions access or prioritizes communication flows. Current debates on net neutrality and the role of Internet service providers (Faris et al., 2016) are therefore related to the structures of the communicative spaces grown by the Internet. Similarly, laws regulating behavior in public space shape the conditions for media and the communicative space, for example, the Spanish Citizen Security Law (2015) criminalizes taking pictures of security forces and the organization of spontaneous protests via social media.

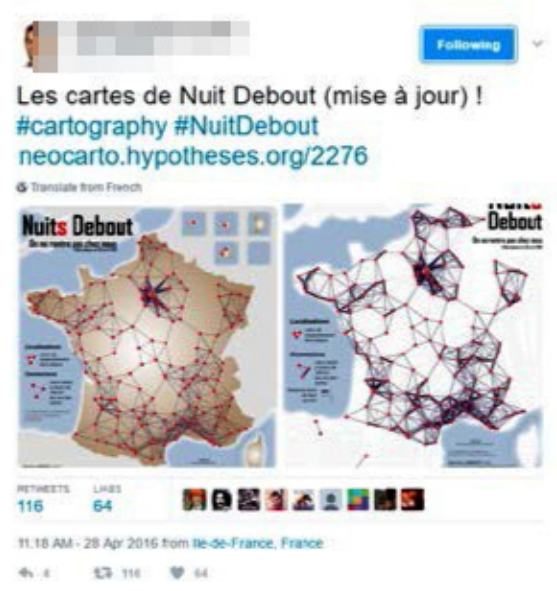

Figure 3. Tweet representing information flows during the Paris protests of \#nuitdebout in 2016. Note: We obtained the user's consent to reprint the tweet; username and faces of depicted people were pixelated to guarantee anonymity.

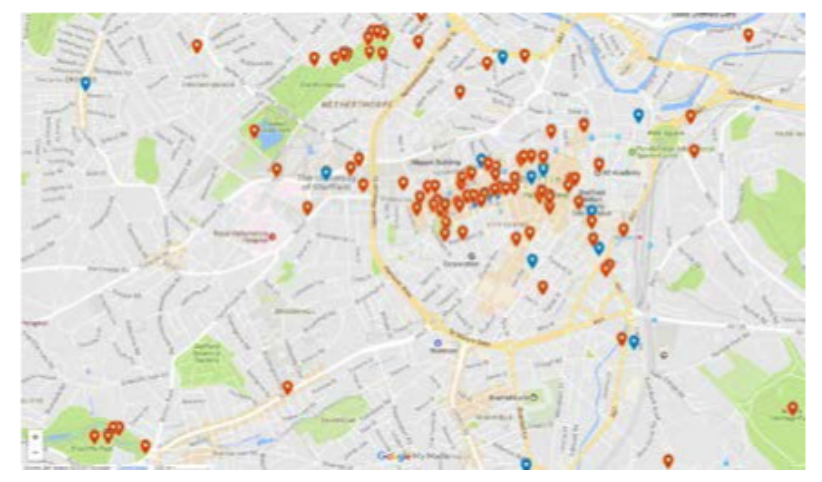

Figure 4. Map visualizing geolocated tweets using the Tramlines festival hashtag.

Structures are fundamental features of the communicative space, and the described three subcategories of barriers, shifts and flows can help orient initial analyses, applying to online and offline interactions, but also to mobility. These categories serve equally for the analysis of festivals and protest, and they could also help to understand architectural and urban planning, as much as it can help the analysis of the interface of an online media participatory platform (Belinskaya \& Rodriguez-Amat, 2020). But the complexity of the communicative space and the role played by structures still deserve further critical and empirical attention. 


\subsection{Exploring Textures and Connections}

Textures and connections are theoretically described and empirically tested but they need further critical discussion. If representations exploit the diversity of views and structures ring-fencing information flows, the role of the analysis of textures is to identify the communications loci and anchor the activity to specific places. 'Textural analysis' is about the value of places and the communication defined and implemented by places themselves (Jansson, 2007). Sites add meaning to whatever happens around them: "Textures of place" orient the analysis after spatial and material turns "towards a view of communication as implicitly grounded, embodied and situated" (Adams \& Jansson, 2012, p. 309). Location does so by expressing the symbolic value of the event (Brantner \& Rodriguez-Amat, 2016). As communicative resources, places are media in their own right, and function as storytellers, be it the Paris Place de la République for the \#nuitdebout demonstrations, or the Spanish Parliament in Madrid, or occupied Wall Street. The location of protests is a political choice, and similarly, websites, media sources, or journalists imprint value onto the information content they spread. They are the loci of a communicative space.

The exploration of textures links to the politics or economics and place(lessness) developed in informational globalization studies. Castells (1989) writes about the historical emergence of the space of flows "superseding the meaning of the space of places" (p. 348). The dichotomy embedded in the notion of 'glocalism' explodes when multiplied by space-sensitive geolocative and mobile media and combined with the possibility of ubiquitous computing (Dourish \& Bell, 2011). This wordpun shows the conceptual effort to grasp a complex phenomenon that involves consideration of place and space. Demonstrations in physical and urban squares, therefore, regain value. An initial textural analysis of a festival in Chania (Greece) suggested three subcategories: communicative capital of place, the location of (shared) memory, and the monumentalized symbolic strategy (Belinskaya et al., 2019). These categories prove that the textural analysis of place rebalances both the diversity of views (representations) and its limitations (structures): The symbolic value of a place is allegedly a consolidated one or an institutionalized representation-hence the notion of communicative capital. But more relevant is the role of textures as the context that embodies a shared (and transcendental) value: There are examples of political and symbolic cultural capital, such as demonstrating around the Spanish Congress in Madrid (\#rodeaelcongreso, September 2012) or of cultural touristic communicative capital, as in the intentional connection of festival venues with tourist sites in Chania, Greece. This shared value can be historical, political, or touristic, but it settles the volatile concept of representations and substantiates the limiting role of the structures.

Somehow opposite to the specific material conditions of textures, the analysis of connections deals with the configurations of the communicative space: "Spaces are structures of opportunity, expectations, and systems of connectivity. The interaction of physical and virtual spaces constructing an imaginary territory ready for action is what is highlighted" (Adams \& Jansson, 2012, p. 312) in the connectivity mode. Connections can be measured; they represent the possibilities of the space to spread information and can theoretically be reduced to a magnitude. These connections define a sort of absolute space (a network of edges) across which any human interaction and any content are possible.

Concepts emerging from social network analysis (see Scott, 2017) help understand the communicative space as a set of connective possibilities that expand beyond the specifics or the limitations of the physical/virtual: concepts like modularity and centrality help establish the relevance of communication nodes that can be topics of a conversation or loci from where the interaction takes place. Connectivity networks can be visualized too and can open analytic possibilities through the identification of connectivity bottlenecks of information, info-spreading nodes, or dead ends. For example, semantic network analysis or co-occurrence techniques can show how a conversation expands thematically on Twitter and how it links to conversations on other sites and locations beyond Twitter. The analysis of the networked public sphere (Faris et al., 2016) would be completed by examining mass media coverage, as every story covering the event has a multiplying effect on its diffusion. In the digital context of geomedia events, the idea of coverage needs to be revisited and the factors that shape the possibilities of impact need to be redefined as part of the update of the public sphere.

\section{Conclusion}

Changes in communication ecosystems have driven reflections that claimed the incorporation of location in media debates and particularly in the idea of the public sphere. This article has reviewed the relevant literature that describes the features of this transformation by focusing on the concepts of the public sphere and on the complexities of space and media-mobile, platformized, and geolocative. This review has also underscored the need to revisit and update the notion of the public sphere. The concept of the public sphere must expand and take into account the location, the space, and its structures, and the devices and technologies shaping the communicative space as conditions for access and participation in the debate. It is equally important to consider these factors as it is to consider the content and the arguments. But still, the concept of the public sphere is a good choice to name that area of contact between us as citizens and the conditions of our own government.

This article suggests an update of the public sphere as a communicative space that is both an interface and an assemblage of a complex set of factors in constant interaction. The notion of interface de-naturalizes the 
public sphere and invites an analysis of its features, its affordances, and its design; the aspect of assemblages liberates and substantiates-by enabling a relational network-the factors that intervene in shaping the conditions for social-communicative interaction. It results from the complexity of the concept of the public sphere that it can do again what it does best: to normatively project the expected conditions for public debate and for democracy.

Analyzing the public sphere, thus, cannot be reduced to considering the content of discourse. If the analysis disregards factors such as the infrastructures, the wiring of the platforms' interfaces, ownership, regulation, conflicting understandings, the symbolic value of the loci of the conversation, or the linguistic landscape and diversity, the analysis will be flawed.

Instead, researchers need to consider the factors that intervene in this quadruple function: representing, structuring, texturizing, and connecting the communicative space. This is what the second part of the article has done, by describing an analytical model that helps articulate these factors. These four modes are functions to look for when intending to explore the conditions of participation in any communicative space, and each specific case may require adapted tools, but the four modes work together by nuancing each other's roles.

These modes are not just sides of a polyhedronthey are analytic gazes that focus on different practices. Representations look for the diversity of views encountered in the several stages of an event, including perceptions of the openness or purpose of the interaction. These views are not sufficient for a proper understanding of the communicative space. It is also necessary to check the structural conditions of participation: Who has access to participate and who does not; who has allowed this to happen and for what purpose? These interactions do not take place in a vacuum but are located on a platform or around a monument. Textural analysis asks how location moderates the conditions for interaction. Finally, the coverage and how the communicative activity spreads must be considered; this is what the analysis of connections does.

These four modes of analysis have already been applied, and this article has illustrated them with examples of research applying them and with a focus on structures. But it is healthy to think of challenging and improving these modes, and references to previous work are also guides for further implementation and development of this toolkit. This is the way to respond, with empirical possibilities, to this conceptual update of the public sphere.

\section{Acknowledgments}

The authors would like to thank the three anonymous reviewers as well as the Academic Editors of the thematic issue for their valuable feedback on the manuscript.

\section{Conflict of Interests}

The authors declare no conflict of interests.

\section{References}

Abernathy, D. (2017). Using geodata and geolocation in the social sciences: Mapping our connected world. Sage.

Adams, P. C., \& Jansson, A. (2012). Communication geography: A bridge between disciplines. Communication Theory, 22(3), 299-318. https://doi.org/ 10.1111/j.1468-2885.2012.01406.x

Arendt, H. (1951). The origins of totalitarianism. Harcourt.

Barreneche, C. (2012). Governing the geocoded world: Environmentality and the politics of location platforms. Convergence, 18(3), 331-351. https://doi.org/ $10.1177 / 1354856512442764$

Belinskaya, Y., Brantner, C., \& Rodriguez-Amat, J. R. (2019). Revisitando la esfera pública (urbana): Un modelo de análisis [Revisiting the (urban) public sphere: A model for analysis]. Sonido, 9(20), 106-133.

Belinskaya, Y., \& Rodriguez-Amat, J. R. (2020). Interfaces of political participation: Challenging the analysis of communicative spaces. In J. M. Jimenez (Ed.), SOTICS 2020: The tenth international conference on social media technologies, communication, and informatics (pp. 1-7). IARIA.

Bennett, W. L., \& Segerberg, A. (2012). The logic of connective action: Digital media and the personalization of contentious politics. Information, Communication \& Society, 15(5), 739-768. https://doi.org/10.1080/ 1369118X.2012.670661

Brantner, C., \& Rodriguez-Amat, J. R. (2016). New 'danger zone' in Europe: Representations of place in social media-supported protests. International Journal of Communication, 10, 299-320.

Castells, M. (1989). The informational city: Information technology, economic restructuring, and the urbanregional process. Blackwell.

Castells, M. (2008). The new public sphere: Global civil society, communication networks, and global governance. The ANNALS of the American Academy of Political and Social Science, 616(1), 78-93. https:// doi.org/10.1177/0002716207311877

Chadwick, A. (2013). The hybrid media system: Politics and power. Oxford University Press.

Chadwick, A., \& Dennis, J. (2017). Social media, professional media and mobilisation in contemporary Britain: Explaining the strengths and weaknesses of the citizens' movement 38 Degrees. Political Studies, 65(1), 42-60. https://doi.org/10.1177/ 0032321716631350

Chadwick, A., Dennis, J., \& Smith, A. (2016). Politics in the age of hybrid media. A. Bruns, G. Enli, E. Skogerbo, A. O. Larsson, \& C. Christensen (Eds.), The Routledge 
companion to social media and politics (pp. 7-22). Routledge.

Colleoni, E., Rozza, A., \& Arvidsson, A. (2014). Echo chamber or public sphere? Predicting political orientation and measuring political homophily in Twitter using big data. Journal of Communication, 64(2), 317-332. https://doi.org/10.1111/jcom.12084

DeLanda, M. (2006). A new philosophy of society: Assemblage theory and social complexity. Continuum.

de Souza e Silva, A. (2006). From cyber to hybrid: Mobile technologies as interfaces of hybrid spaces. Space and Culture, 9(3), 261-278. https://doi.org/10.1177/ 1206331206289022

Despard, E. (2016). A materialist media ecological approach to studying urban media in/of place. In S. Kubitschko \& A. Kaun (Eds.), Innovative methods in media and communication research (pp. 37-58). Springer.

de Waal, M. (2014). The city as interface: How new media are changing the city. Nai010.

Dodge, M. (2014). Mapping and geovisualization. In S. C. Aitken \& G. Valentine (Eds.), Approaches to human geography: Philosophies, theories, people and practices (2nd ed., pp. 289-305). Sage.

Dourish, P., \& Bell, G. (2011). Divining a digital future: Mess and mythology in ubiquitous computing. MIT Press.

Eckardt, F. (Ed.). (2008). Mediacity: Situations, practices and encounters. Frank \& Timme.

Elwood, S., \& Leszczynski, A. (2013). New spatial media, new knowledge politics. Transactions of the Institute of British Geographers, 38(4), 544-559. https://doi. org/10.1111/j.1475-5661.2012.00543.x

Faris, R., Roberts, H., Etling, B., Othman, D., \& Benkler, Y. (2016). Net neutrality: The role of the networked public sphere in the U.S. net neutrality policy debate. International Journal of Communication, 10, 5839-5864.

Farman, J. (2012). The mobile interface of everyday life: Embodied space and locative media. Routledge.

Ferree, M. M., Gamson, W. A., Gerhards, J., \& Rucht, D. (2002). Four models of the public sphere in modern democracies. Theory and Society, 31(3), 289-324. https://doi.org/10.1023/A:1016284431021

Fraser, N. (1996). Multiculturalism and gender equity: The US "difference" debates revisited. Constellations, 3(1), 61-72. https://doi.org/10.1111/j.14678675.1996.tb00043.x

Frith, J. (2017). Invisibility through the interface: The social consequences of spatial search. Media, Culture \& Society, 39(4), 536-551. https://doi.org/10.1177/ 0163443717698871

Garnham, N. (2007). Habermas and the public sphere. Global Media and Communication, 3(2), 201-214.

Geiger, R. S. (2009). Does Habermas understand the Internet? The algorithmic construction of the blogo/public sphere. Gnovis: A Journal of Communication, Culture, and Technology, 10(1), 1-29.
Goodchild, M. (2009). NeoGeography and the nature of geographic expertise. Journal of Location Based Services, 3(2), 82-96. https://doi.org/10.1080/ 17489720902950374

Grech, G. (2015, September 8). Cities as platforms. Social Tech Crunch. http://social.techcrunch.com/2015/08/ 07/cities-as-platforms

Habermas, J. (1974). The public sphere: An encyclopedia article (1964). New German Critique, 3, 4-55.

Habermas, J. (1991). The structural transformation of the public sphere: An inquiry into a category of bourgeois society. MIT Press.

Habermas, J. (2006). Political communication in media society: Does democracy still enjoy an epistemic dimension? The impact of normative theory on empirical research. Communication Theory, 16(4), 411-426. https://doi.org/10.1111/j.1468-2885. 2006.00280.x

Harvey, D. (2010). Social justice and the city (Vol. 1). University of Georgia Press.

Humphreys, L. (2011). Who's watching whom? A study of interactive technology and surveillance. Journal of Communication, 61(4), 575-595. https://doi.org/ 10.1111/j.1460---2466.2011.01570.x

losifidis, P. (2011). The public sphere, social networks and public service media. Information, Communication \& Society, 14(5), 619-637. https://doi.org/ 10.1080/1369118X.2010.514356

Jacobs, R. N. (1999). Race, media and civil society. International Sociology, 14(3), 355-372. https://doi.org/ 10.1177/0268580999014003008

Jansson, A. (2007). Texture. European Journal of Cultural Studies, 10(2), 185-202. https://doi.org/ $10.1177 / 1367549407075904$

Jethani, S., \& Leorke, D. (2013). Ideology, obsolescence and preservation in digital mapping and locative art. International Communication Gazette, 75(5/6), 484-501. https://doi.org/10.1177/1748048513491 904

Lapenta, F. (2011). Geomedia: On location-based media, the changing status of collective image production and the emergence of social navigation systems. Visual Studies, 26(1), 14-24. https://doi.org/ 10.1080/1472586X.2011.548485

Lefebvre, H. (1991). The production of space. Blackwell.

Manovich, L. (2001). The language of new media. MIT Press.

Massey, J., \& Snyder, B. (2012). Occupying wall street: Spaces of political action. Places Journal. https://placesjournal.org/article/occupying-wallstreet-places-and-spaces-of-political-action

Morley, D. (2009). For a materialist, non-media-centric media studies. Television \& New Media, 10(1), 114-116. https://doi.org/10.1177/152747640832 7173

Mouffe, C. (2005). On the political. Routledge.

Negt, O., \& Kluge, A. (1973). Öffentlichkeit und Erfahrung: Zur Organisationsanalyse von bürgerlicher und pro- 
letarischer Öffentlichkeit [Public sphere and experience: Toward an analysis of the bourgeois and proletarian public sphere]. Suhrkamp.

Rainie, L., \& Wellman, B. (2012). Networked: The new social operating system. MIT Press.

Rodriguez-Amat, J. R., \& Brantner, C. (2016). Space and place matters: A tool for the analysis of geolocated and mapped protests. New Media \& Society, 18(6), 1027-1046. https://doi.org/10.1177/ 2F1461444814552098

Sadowski, J. (2014, December 28). The architecture of dissent. Urban design influences how public protests can take root. Aljazeera America. http://america. aljazeera.com/opinions/2014/12/urban-designarchitectureprotests.html

Sassen, S. (2006). Territory, authority, rights: From medieval to global assemblages. Princeton University Press.

Schlesinger, P. (1999). Changing spaces of political communication: The case of the European Union. Political Communication, 16(3), 263-279. https://doi.org/ $10.1080 / 105846099198622$

Scolari, C. A. (2018). Las leyes de la interfaz: Diseño, ecología evolución, tecnología [The laws of the interface: Design, ecology, evolution, technology]. Edito- rial Gedisa.

Scott, K. (2017). Social network analysis (4th ed.). Sage.

Sparks, C. (2001). The Internet and the global public sphere. Cambridge University Press.

Thomas, G., \& Wyatt, S. (1999). Shaping cyberspace: Interpreting and transforming the Internet. Research Policy, 28(7), 681-698. https://doi.org/10.1016/ S0048-7333(99)00016-5

Tonkiss, F. (2005). Space, the city and social theory: Social relations and urban forms. Polity Press.

Treré, E. (2016). The dark side of digital politics: Understanding the algorithmic manufacturing of consent and the hindering of online dissidence. IDS Bulletin, 41(1), 127-138. https://doi.org/10.19088/ 1968-2016.111

Treré, E. (2018). Hybrid media activism: Ecologies, imaginaries, algorithms. Routledge.

Urry, J. (2007). Mobilities. Polity Press.

Van Dijck, J., Poell, T., \& De Waal, M. (2018). The platform society: Public values in a connective world. Oxford University Press.

Walzer, M. (1999). On toleration. Yale University Press.

Zeffiro, A. (2012). A location of one's own: A genealogy of locative media. Convergence, 18(3), 249-266. https://doi.org/10.1177/1354856512441148

\section{About the Authors}

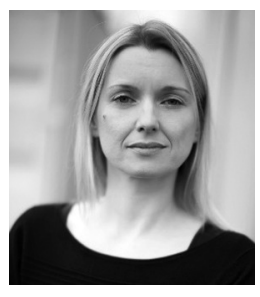

Cornelia Brantner (PhD) is Senior Lecturer at the Department of Geography, Media and Communication at Karlstad University. Her teaching portfolio and research profile cover visual communication, geomedia and digital communication, public spheres and (in)equalities, science communication, as well as qualitative and quantitative methods.

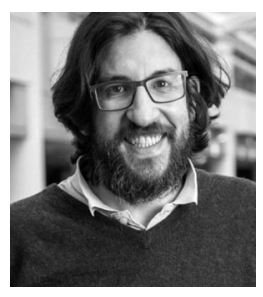

Joan Ramon Rodríguez-Amat (PhD) is Principal Lecturer and Research and Innovation Lead in the Department of Media Arts and Communication at Sheffield Hallam University. His research focuses on the combination of the three facets of the communicative space: communities (i.e., fandom), governance (i.e., democracy), and technologies (i.e., geomedia).

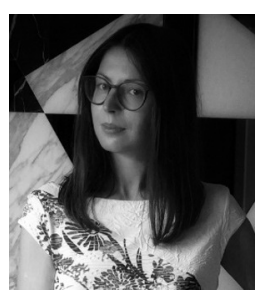

Yulia Belinskaya (MA) is Prae-Doc Researcher at the Department of Communication, University of Vienna. She received her first Master's degree from St. Petersburg University of Technology and her second from Stockholm University. Her current work covers the governance of communicative spaces, cultural communication, including social media activity, digital media in hybrid regimes, freedom of expression, pornography and obscenity, restrictive media policies, and ethics of communication. 